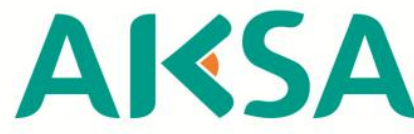

JURNAL DESAIN KOMUNIKASI VISUAL
AKSA JURNAL DESAIN KOMUNIKASI VISUAL

ISSN: 2615-1111 (online)

Available online at:

http://jurnalaksa.stsrdvisi.ac.id

\title{
PERANCANGAN MASKOT SEBAGAI STRATEGI BRAND ACTIVATION KLUB SEPAKBOLA PSIM JOGJA
}

\author{
Ditya Fajar Rizkizha \\ Pascasarjana Institut Seni Indonesia Yogyakarta \\ dityarizkizha@gmail.com
}

\begin{tabular}{|c|c|}
\hline ARTICLE INFO & ABSTRACT \\
\hline $\begin{array}{l}\text { Article history: } \\
\text { Received: } 1 \text { Desember } 2018 \\
\text { Revised: } 28 \text { Februari } 2019 \\
\text { Accepted: } 15 \text { Maret } 2019\end{array}$ & $\begin{array}{l}\text { Yogyakarta, a town still exist will including its culture and tradition, } \\
\text { have a football team local named PSIM Jogja. Identity PSIM Jogja } \\
\text { attaching with blue and white, and Tugu Jogja to represent the club } \\
\text { it comes from the town of Jogja. This can be seen through logo. }\end{array}$ \\
\hline $\begin{array}{l}\text { Keywords: } \\
\text { Brand Activation } \\
\text { Mascot } \\
\text { PSIM Jogja }\end{array}$ & $\begin{array}{l}\text { PSIM Jogja have the logo club, classic it is meaningful. Historically } \\
\text { the club PSIM cannot be separated by means of Keraton Jogja. But, } \\
\text { to nickname attaching in PSIM Jogja itself is not the point where the } \\
\text { brand image. Several media often mentioned differently. This has } \\
\text { touched frequently make a question ask mind forces loyal to PSIM } \\
\text { Jogja. } \\
\text { Of a question that need of the effort to create and strengthened } \\
\text { image PSIM Jogja through a strategy of branding called brand } \\
\text { activation. See this difficulty researchers consider mascot design as } \\
\text { part of its brand activation done to realize vision and the mission of } \\
\text { PSIM Jogja as a football club "Warisane Simbah", this business } \\
\text { also to care for existence PSIM Jogja in various football Indonesia } \\
\text { and close the club with audience. }\end{array}$ \\
\hline
\end{tabular}

\section{PENDAHULUAN}

Sepakbola saat ini telah berkembang dan mendudukan dirinya sebagai olahraga paling populer di dunia. Dari semula yang bertujuan untuk hiburan dan aktivitas untuk menjaga kesehatan tubuh, namun pada saat ini sepakbola juga telah berkembang menjadi suatu industri bisnis dengan pemasukan yang besar. Sumber penghasilan ini berasal dari pendapatan tiket, merchandise, hak penyiaran televisi, serta melakukan co-branding (bekerja sama dengan brandbrand lain).

Sebuah klub lokal kota Yogyakarta, PSIM atau Perserikatan Sepakbola Indonesia Mataram lahir pada tanggal 5 September 1929 di Yogyakarta, pada awal berdirinya bernama Persatuan Sepakraga Mataram (PSM). Pada awal dibentuknya, PSIM Jogja adalah organisasi 
pergerakan perjuangan kemerdekaan Indonesia melalui bidang olahraga. Nama Mataram digunakan karena Yogyakarta merupakan pusat pemerintahan kerajaan Mataram (Ngayogyakarta Hadiningrat). Kemudian pada tanggal 27 Juli 1930 nama PSM diubah menjadi PSIM seperti yang dikenal sekarang.

Dalam perjalanannya, PSIM Jogja mengalami grafik yang naik turun, hal itu dapat dilihat dari segi prestasi maupun dalam keuangan klub. Dalam 5 tahun terakhir di setiap kompetisi sepakbola liga Indonesia, PSIM sudah tidak lagi menggunakan dana APBD, hal ini juga dialami setiap klub di Indonesia. Regulasi PSSI menuntut setiap klub untuk mandiri dan bekerja secara professional. Sampai saat ini pun pengoperasian PSIM Jogja hanya memanfaatkan pendapatan dari segi sektor tiket, sektor lain seperti merchandise dan sponsor belum dapat dimaksimalkan manajemen PSIM dikarenakan minimnya sumber daya manusia yang menguasai sektor tersebut.

Namun dibalik itu semua, PSIM Jogja atau yang biasa dijuluki Laskar Mataram, menyimpan keunikan tersendiri dibanding klub sepakbola di kota-kota lain. Seperti contoh, masih memegang teguh tradisi ziarah ke makam Raja-Raja di Imogiri sebagai bentuk permohonan restu sebelum mengarungi liga Indonesia. Kemudian, PSIM juga menyematkan batik parang rusak di jersey setiap musimnya. PSIM bahkan menjadi trendsetter dalam penyematan batik di jersey ini, yang kemudian diikuti tim-tim lain di Indonesia berdasarkan ciri khas masing-masing daerah.

Secara identitas, PSIM Jogja lekat dengan warna biru dan kuning, serta Tugu Jogja yang merepresentasikan klub ini berasal dari kota Jogja. Hal ini dapat dilihat melalui logo klub. PSIM Jogja mempunyai logo klub yang klasik, namun sangat bermakna. Dalam sejarahnya logo klub PSIM ini tidak dapat dipisahkan dengan simbol kelambangan Keraton Jogja. Saat didirikan, Sultan Hamengkubuwono VIII memegang kendali pemerintahan, keterkaitannya dapat dilihat dari peraturan dan kebijakan pada saat itu. Campur tangan dan andil Keraton Jogja mewarnai dalam pembuatan logo PSIM Jogja, dan logo tersebut merupakan makna peninggalan kesimbolan Jawa.

Untuk julukan yang tersemat di PSIM Jogja sendiri masih belum memunculkan brand image yang kuat. Beberapa media sering kali menyebutkan secara berbeda, seperti Laskar Mataram, Parang Biru, Naga Jawa, Warisane Simbah, Ksatria Mataram, serta Gatotkaca. Hal ini lah yang acap kali menimbulkan sebuah pertanyaan pada benak pendukung setia PSIM Jogja. Dari sebuah pertanyaan itu perlu adanya upaya untuk menciptakan dan menguatkan citra PSIM Jogja melalui strategi branding yang disebut brand activation. Brand activation merupakan aktivitas mendekatkan dan interaksi merek dengan konsumen yang menarik perhatian guna 
menciptakan buzz marketing atau pembicaraan (word of mouth) yang positif terhadap kesadaran merek. Sebuah brand akan dinyatakan berhasil apabila konsumen secara sadar ataupun tidak sadar memilih suatu brand untuk memenuhi kebutuhannya. Tujuan dari brand activation menurut Direct Marketing Association yaitu, mengemukakan beberapa fungsi brand activation yaitu memperkuat brand positioning dan image sebuah brand, menarik perhatian dari pelanggan pesaing, menunjukan kelebihan brand dibanding brand kompetitor, menjaga dan meningkatkan hubungan serta loyalitas dari pelanggan, serta menciptakan brand awareness yang tinggi dan instan.

Dari beberapa pilihan strategi brand activation yang ada, penulis memilih perancangan maskot untuk dijadikan hasil pada karya ini, karena maskot merupakan salah satu elemen dari brand identity untuk meningkatkan awareness pada sebuah brand. Pada perkembangannya, maskot adalah bagian dari strategi brand dari sebuah institusi. Maskot tidak hanya hadir sebagai penghias atau sebuah badut yang lucu, namun lebih dari itu, maskot diharapkan dapat 'hidup' dan sekaligus berperan 'menghidupkan' aktivitas komunitasnya. Paradigma desain maskot yang sebelumnya dipandang sebelah mata, kini dapat leluasa dikembangkan menjadi efektif dan berdaya guna.

Melihat permasalahan tersebut, maka penulis akan membuat penelitian tentang bagaimana cara merancang brand activation sebagai sebuah strategi branding yang mampu menguatkan identitas dari PSIM Jogja. Penulis berharap dengan adanya perancangan ini dapat membawa dampak yang luar biasa pada ilmu desain komunikasi visual, khususnya tentang kekuatan brand image melalui strategi brand activation untuk dapat mempengaruhi awareness dan pengetahuan masyarakat terhadap perusahaan, brand, atau produk yang ditawarkan.

\section{METODE PENCIPTAAN}

\section{a. Observasi/pengamatan}

Pengamatan langsung ke objek yang dituju. Dalam pengamatan/observasi ini masih bersifat selintas, dan masih perlu diperkuat dengan data lain seperti data pustaka, wawancara, dokumentasi, dan sebagainya.

\section{b. Pengumpulan Informasi}

Sumber data perihal sejarah, makna logo PSIM terdiri sumber lisan, internet dan sumber tertulis. Sumber lisan didapat berdasar wawancara langsung dengan sumber penelitian yakni khususnya dengan Ketua Umum PSIM Jogja, sesepuh PSIM, ketua Asprov PSSI DIY dan sebagian komunitas supporter PSIM Jogja. 
Sumber tertulis didapat dari:

- Data pustaka; berupa arsip sejarah PSIM Jogja, sosial media PSIM dan website PSIM.

- Data dari media massa; berupa surat kabar dan majalah bulanan PSIM.

- Dokumentasi berupa verbal dan visual.

- Kuesioner yang dibagi kepada 600 responden untuk mengetahui hasil riset perancangan maskot PSIM Jogja.

\section{PEMBAHASAN}

\section{a. Konsep Perancangan}

Dalam perancangan ini konsep yang digunakan untuk mengatasi masalah branding PSIM Jogja yaitu dengan menggunakan strategi brand activation. Brand activation adalah cara berkomunikasi untuk mendekatkan brand dengan target pasar melalui kegiatan yang membangkitkan interaktifitas dan ketertiban target bersama brand. Brand activation termasuk isu baru dalam bidang komunikasi pemasaran. Pada tahun-tahun terakhir ini, strategi tersebut telah menjadi tren dalam memasarkan tidak hanya sebuah produk, tetapi juga sebuah brand. Brand activation ditujukan untuk membangun merek (brand building) sekaligus meningkatkan angka penjualan produk agar dapat membuat daya tarik konsumen dengan menggunakan kegiatan sebuah brand (Kotler, 2004:10).

Menurut Wheeler (2009:46) salah satu elemen (pictorial mark) dari brand identity adalah maskot. Maskot adalah personifikasi dari brand dalam wujud karakter tertentu dengan sifat dan ciri khas yang mewakili brand tersebut. Maskot dapat menjadi alat komunikasi sekaligus diferensiasi yang dapat menjadi suatu media promosi yang efektif dalam konteks "awareness" untuk jangka pendek, dan "loyalty” untuk jangka panjang. Maskot yang efektif adalah maskot yang mampu menggambarkan sebuah kepribadian merek, filosofi, membawa gambaran visi dan misi, serta mampu menjadi bagian dari publik itu sendiri.

Maskot yang dibuat secara sederhana dan berkarakter dapat meningkatkan corporate image sebagai gambaran tentang aktualisasi interaksi produk terhadap konsumen dan dinamisasinya yang memberikan dampak yang sangat baik. Menurut Kent Wertime (2003:116) maskot memiliki relevansi komersial yang luar biasa. Karena berkapasitas memicu ingatan dan membentuk koneksi dengan elemen-elemen yang lebih fundamental dari otak. Teknik ini muncul dalam berbagai bentuk familiar sampai-sampai sebagian audiens tidak mengenalinya sebagai pembantu ingatan. Jadi, maskot merupakan salah satu strategi brand activation yang membuat brand nampak unik ditengah-tengah brand lainnya. Maskot dapat mewakili karakter dan pribadi 
dari brand itu sendiri dan membuat brand tersebut beda dengan yang lainnya. Banyak pakar periklanan yang meyakini bahwa salah satu representasi paling efektif dari sebuah brand adalah maskot.

\section{b. Proses Perancangan}

Proses yang dilakukan setelahnya yakni dengan cara menyusun strategi kreatif, yakni menyampaikan pesan yang akan dibuat dalam sebuah ide dan konsep perancangan karena tujuan utamanya ialah bagaimana merebut perhatian target audience dengan media yang dipergunakan untuk menyampaikan pesan tersebut.

\section{Isi Pesan (what to say)}

Isi pesan berupa informasi terkait PSIM Jogja sebagai sebuah klub sepakbola yang diwariskan oleh nenek moyang kepada penerus generasi selanjutnya.

\section{Bentuk Pesan (how to say)}

Bentuk pesan tidak hanya dihadirkan dalam pesan verbal saja, namun pesan visual juga harus dihadirkan dan harus lebih memiliki daya tarik yang utama. Pesan visual dapat diaplikasikan pada media utama dan media pendukung. Ada 4 hal yang mendasari dalam memilih bentuk pesan visual, yaitu:

\section{a. Tata Visual}

Pemberian tata visual dalam perancangan komunikasi visual ini bertujuan untuk menampilkan gambar dan teks agar menjadi komunikatif guna memudahkan target audience menerima informasi yang diberikan. Unsur tata visual pada perancangan ini diperlukan untuk menarik perhatian, memberikan penekanan terhadap elemen atau pesan yang akan disampaikan.

\section{b. Ilustrasi}

Ilustrasi dibuat dengan menggunakan visual vector dengan gambar sederhana untuk memudahkan dan meringankan penyampaian pesan dan informasi kepada target audience dengan adannya point of interest di dalamnya.

Pemilihan karakter untuk maskot PSIM Jogja berdasarkan hasil observasi, wawancara dan dokumentasi menetapkan Naga Jawa sebagai karakter yang mencerminkan kepribadian PSIM Jogja. Pemilihan karakter Naga Jawa dipilih berdasarkan watak dari tahun berdiri PSIM Jogja yaitu tahun 1929 atau 1860 Jawa, hal itu biasa disebut candrasengkala. Candrasengkala merupakan simbolisasi angka tahun, dan menggambarkan watak atau karakter dari tahun itu sendiri. Angka 1 mempunyai watak wani. Angka 8 mempunyai watak Naga. Angka 6 Rasa, dan 
angka 0 mempunyai watak Luhur, yang kemudian dibaca Luhuring Rasa Naga Wani (kemuliaan hati naga yang berani).

\section{c. Warna}

Pada perancangan ini akan didominasi warna biru dan kuning. Hal ini mengacu pada logo dan warna identik yang lekat dengan PSIM Jogja saat ini. Namun disamping itu, pemberian warna tidak seutuhnya dominan warna biru dan kuning saja, warna seperti coklat tua dan coklat muda akan dimasukkan untuk memberikan kesan klasik. Warna biru mewakili kesetiaan atau keloyalitasan terhadap klub kebanggaan. Sedangkan warna kuning mewakili kehangatan dan penuh energi.

\section{d. Tipografi}

Jenis huruf yang digunakan yakni menggunakan karakter huruf Serif dan San Serif. Jenis huruf ini akan digunakan sebagai tagline. Untuk tagline yang akan digunakan adalah nama untuk sang maskot yaitu, “Raynor”. Raynor sendiri diambil dari bahasa sansekerta yang berarti prajurit yang tangguh. Prajurit disini memiliki arti prajurit yang ada di dalam Keraton Jogja. Watak dari prajurit Keraton adalah "Watak Ksatriya" atau "Wataking Satriya Ngayogyakarta" yang dilandasi dengan kredo (sesanti) Sawiji, Greget, Sengguh, Ora Mingkuh.

\section{c. Info-info Dasar}

\section{Strategi Media}

Demi mencapai tujuan media diperlukan suatu strategi media yang dapat mendukung perancangan ini sehingga media-media yang digunakan menjadi efektif dan efisien. Strategi media merupakan cara untuk memecahkan masalah dari analisis pemilihan tujuan media. Oleh karena itu, dalam pemilihan media dibagi menjadi dua, yaitu media utama dan media pendukung.

\section{a. Media utama}

\section{Website}

Website adalah suatu halaman web yang saling berhubungan yang umumnya berisikan informasi dalam bentuk digital baik itu teks, gambar maupun animasi yang disediakan secara perorangan, kelompok, atau organisasi. Media ini menjadi bagian untuk menginformasikan perancangan maskot melalui akun website resmi PSIM Jogja.

\section{Media Sosial Instagram, Facebook, dan Twitter}

Ketiga media sosial ini dipilih karena sangat efektif dalam penyampaian suatu pesan dan informasi. Terlebih juga pada saat ini target audience lebih banyak menggunakan ketiga situs ini 
dari sekian banyak situs jejaring media sosial lainnya. Melalui media ini akun official dengan mudah berinteraksi dengan para fans nya melalui comments dan tuitan yang di share oleh para fans PSIM, serta dapat menjangkau audience yang lebih luas dan menciptakan strategi yang lebih efektif untuk mempromosikan sebuah produk.

\section{b. Media Pendukung}

\section{Billboard}

Bentuk promosi iklan luar ruang dengan ukuran besar. Billboard termasuk model iklan luar ruang yang paling banyak digunakan.

\section{Transit Ad}

Merupakan suatu media luar ruang yang diletakkan pada salah satu tempat strategis, biasanya di halte bus atau di tempat yang dilalu-lalang orang banyak.

\section{Sintesis}

Mengacu pada teori Alina Wheeler, hasil dari penelitian ini adalah karya berupa perancangan maskot PSIM Jogja sebagai alat komunikasi dan diferensiasi yang efektif dalam konteks membangun branding.
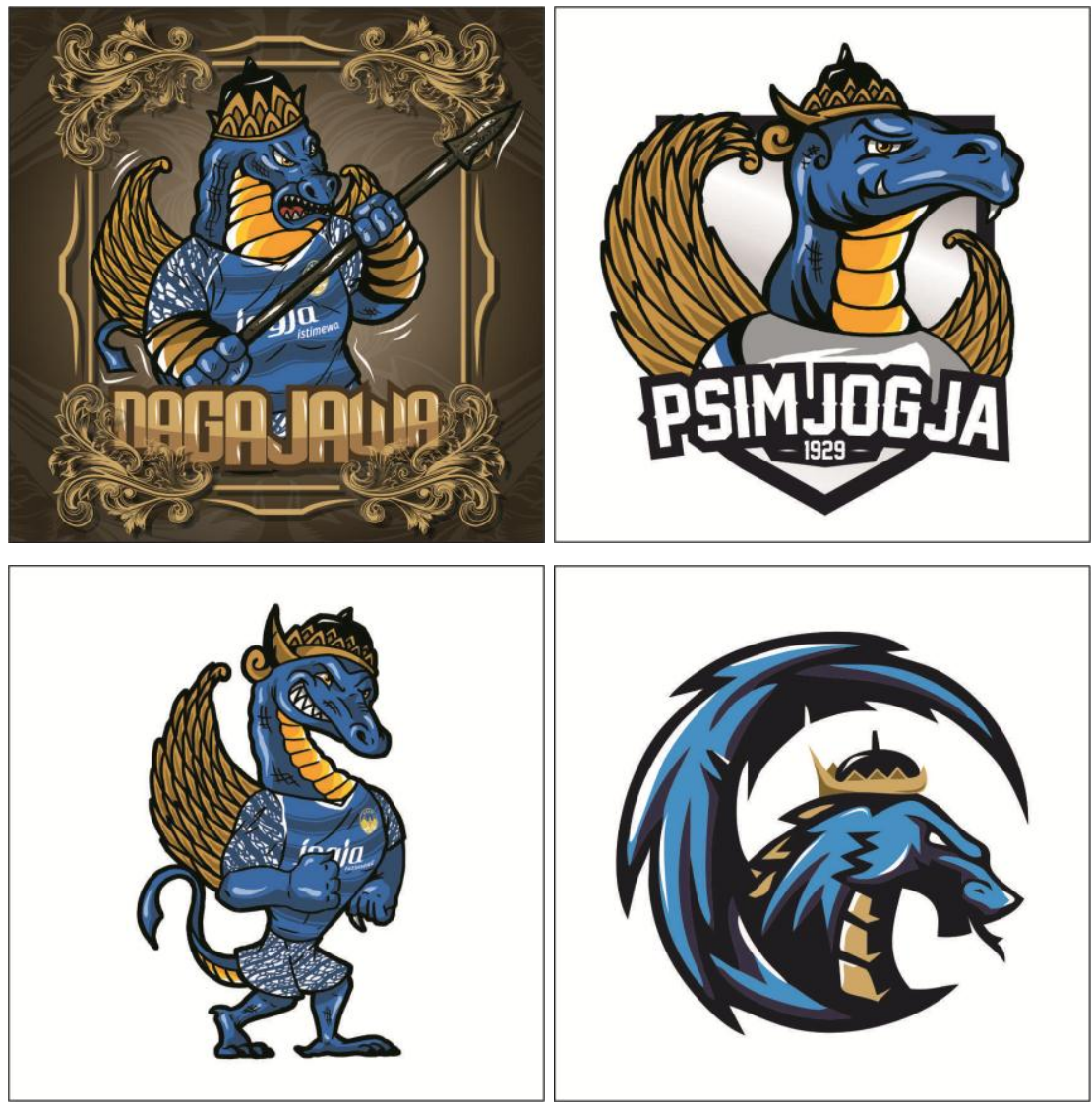

Gambar. 1 Maskot PSIM Jogja

(Sumber: Dokumentasi penulis) 
Kemudian maskot ini akan diperkenalkan kepada masyarakat melalui media utama yaitu, website dan media sosial, serta media pendukung yaitu, billboard dan Transit Ad. Menurut David Aaker kemampuan digital meliputi situs jaringan, blog, media sosial, video online, dan lain-lain telah menjadi keharusan bagi organisasi-organisasi yang ingin membangun atau meningkatkan brand mereka, maka media adalah kekuatan yang luar biasa hebat untuk brand building.
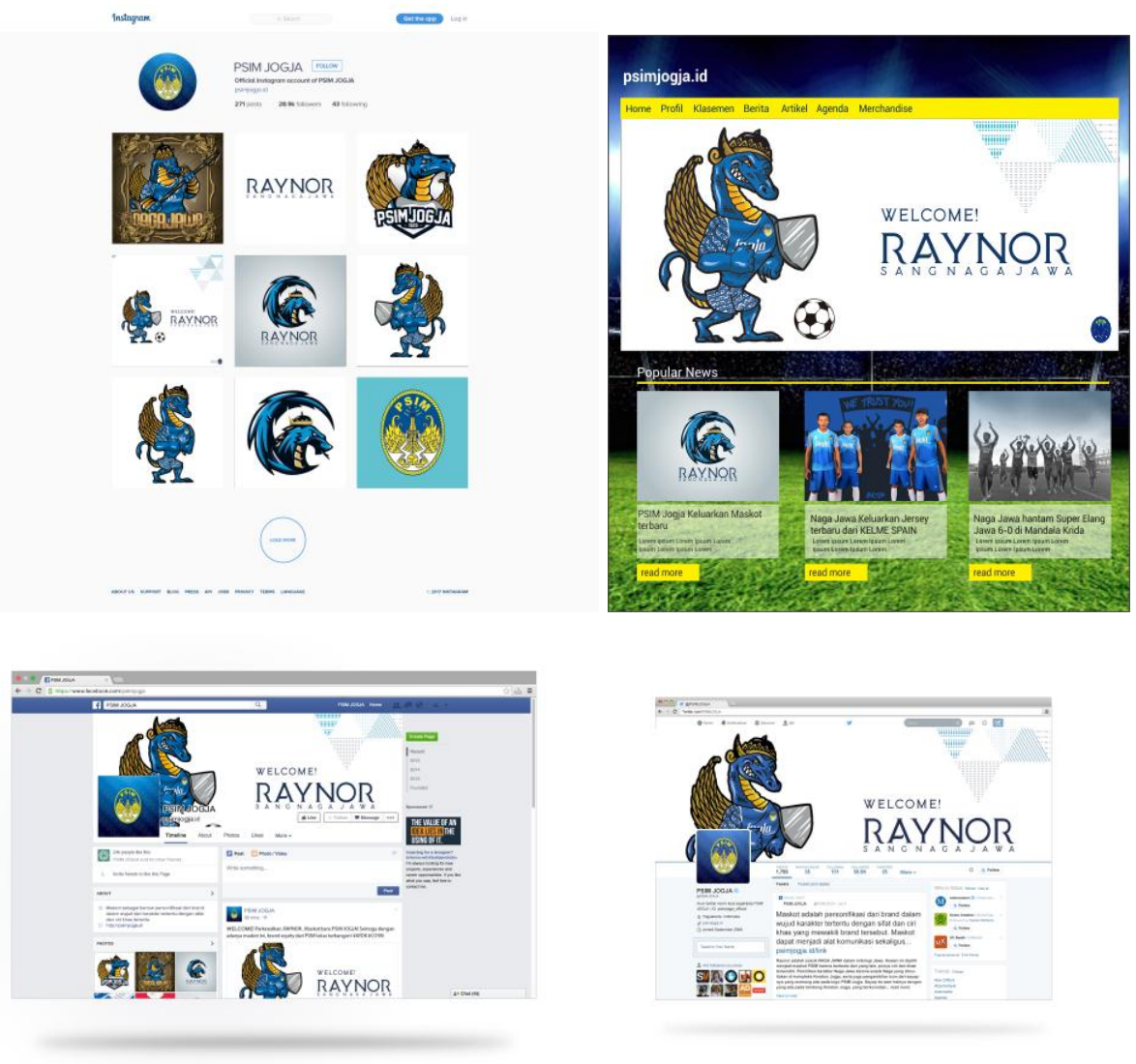

Gambar. 2 Memperkenalkan maskot PSIM Jogja melalui website dan dedia sosial (Sumber: Dokumentasi penulis)
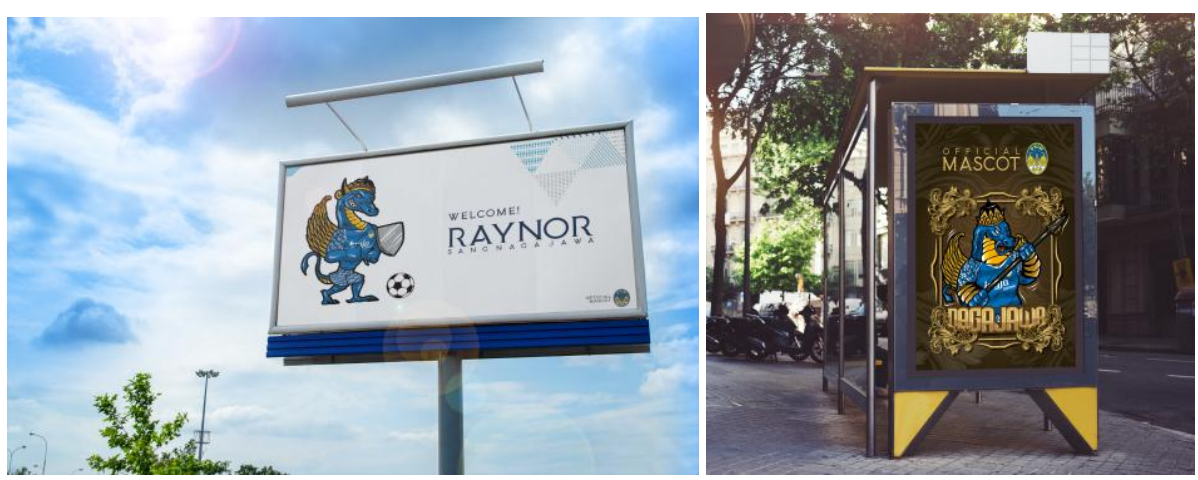

Gambar. 3 Memperkenalkan maskot PSIM Jogja melalui billboard dan transit ad (Sumber: Dokumentasi penulis) 


\section{KESIMPULAN}

Berdasarkan teori-teori dan analisa yang telah dikemukakan pada bab sebelumnya, dan mendasari rumusan permasalahan pada penelitian mengenai penerapan brand activation untuk menguatkan image PSIM Jogja, maka diperoleh kesimpulan bahwa peneliti melihat adanya dua permasalahan utama yaitu, belum terbentuknya kekuatan brand dan identitas visual yang representattif serta kurangnya eksistensi PSIM Jogja di kalangan masyarakat DIY.

Melihat permasalahan itu, peneliti menganggap perancangan maskot sebagai bagian dari strategi brand activation yang dilakukan untuk mewujudkan visi dan misi dari PSIM Jogja sebagai klub sepakbola "Warisane Simbah", usaha ini juga untuk merawat eksistensi PSIM Jogja di kancah persepakbolaan Indonesia serta mendekatkan klub dengan target sasaran.

Dengan pertimbangan estetis, desain maskot Raynor dirancang unik dengan warna identik PSIM Jogja, serta menampilkan rancangan maskot yang gagah, sehingga menimbulkan efek yang penuh semangat bagi orang yang melihatnya. Desain maskot Raynor dirancang dengan mempelajari latar belakang tradisi dan budaya lokal di kota Jogjakarta yang sangat kental dengan nuansa Jawanya. Desain maskot PSIM Jogja juga telah memenuhi kriteria sebagai desain yang unik, khas, dan tetap mengusung simbol Jawa, serta menyematkan batik parang Rusak sebagai pakaiannya.

\section{DAFTAR PUSTAKA}

Aaker, David. (2002). Aaker on Branding: 20 Prinsip Esensial Mengelola dan Mengembangkan Brand. Jakarta: Gramedia.

Junaedi, Fajar. (2014). Merayakan Sepakbola: Fans, Identitas dan Media Jilid 1. Yogyakarta: Fandom

Kotler, Philip. (2002). Manajemen Pemasaran, Jilid 2, Penerjemah: Hendra Teguh, dkk. Jakarta: Prenhallindo.

Lanang, Achmad dkk. (2016). Sepakbola 2.0. Yogyakarta: Fandom.

Moeleong, Lexy J. (2002). Metode Penelitian Kualitatif. Bandung: Rosda.

Morel, P., Preisler, P. dan Nystrom, A. (2002). Brand Activation. Stockholm: Starsky Insight.

Rustan, Surianto. (2009). Mendesain Logo. Jakarta: PT Gramedia Pustaka Utama.

Sanyoto, Ebdi Sadjiman. (2005). Dasar-Dasar Tata Rupa dan Desain. Yogyakarta: CV. Arti Bumi Intaran.

Suhandang, Kustadi. (2010). Periklanan: Manajemen, Kiat dan Strategi. Bandung: Nuansa. Sunaryo, Aryo. (2013). Rerupa Sengkalan: Kajian Estetis dan Simbolis Sengkalan Memet Keraton Yogyakarta. Yogyakarta. Penerbit Ombak. 
Tinarbuko, Sumbo. (2015). DEKAVE Desain Komunikasi Visual-Penanda Zaman Masyarakat Global. Jakarta: CAPS

Tjiptono, Fandi. (2014). Branding \& Brand Longevity di Indonesia. Yogyakarta: C.V Andi Offset.

Wartime, Kent. (2003). Building Brands and Believers. Jakarta: Erlangga.

Wheeler, Alina. (2009). Designing Brand Identity Third Edition. New Jersey: John Willey \& Sons, Inc.

\section{Interrnet}

www.brandactivation.ca/brand-activationtrade.html (5 April 2017)

aristanaprawira.wordpress.com (20 April 2017)

blog.sribu.com/peran-desain-maskot-untuk-kesuksesan-sebuah-brand/ (18 Mei 2017) 